\title{
Morphological variation of Cosmos bipinnatus (Asteraceae) and its relation to abiotic variables in central Mexico
}

\author{
Maribel Paniagua-lbáñez ${ }^{1,2}$, Alfredo López-Caamal², Patricia Mussali-Galante³, Enrique Sánchez-Salinas³,
} Ma. Laura Ortiz-Hernández ${ }^{3}$, Rolando Ramírez-Rodríguez ${ }^{1}$ and Efraín Tovar-Sánchez ${ }^{1 *}$

\begin{abstract}
Background: Morphological variability can lead to serious taxonomic problems in species with wide distribution ranges. Although morphological variability is partly due to ontogenetic programming, abiotic variables can also exert a significant effect on micro- and macromorphological characters. In this paper, we studied the morphological variability (43 characters) of Cosmos bipinnatus associated to different vegetation types in central Mexico. We searched for significant correlations between the overall morphology of C. bipinnatus and abiotic variables such as altitude and soil parameters ( $\mathrm{pH}$, organic matter content, $\mathrm{NH}_{4}, \mathrm{NO}_{3}, \mathrm{PO}_{4}$, total $\mathrm{N}$ and total $\mathrm{P}$ content). We also analyzed the Simplified Relative Distance Plasticity Index $\left(\mathrm{RDPI}_{\mathrm{s}}\right)$.

Results: Locality had a significant effect in all but three morphological characters measured. Also, $71.43 \%$ of the characters had a significant correlation with at least one abiotic variable. $\mathrm{PO}_{4}$ content was significantly correlated with paleae characters, while $\mathrm{pH}$ had a significant effect in ligule coloration. Discriminant function analysis revealed that C. bipinnatus individuals collected at grasslands and Pinus forests form separate clusters, while individuals collected at scrubs and Quercus forests showed considerable overlap. The RDPI ${ }_{s}$ across all sites showed very low levels of plasticity in almost all characters.

Conclusions: Some abiotic variables (altitude, soil $\mathrm{NH}_{4}$ and $\mathrm{PO}_{4}$ content, and soil $\mathrm{pH}$ ) largely contribute to the differential phenotypic expression of C. bipinnatus in central Mexico. However, we found that the number of external phyllaries, the trichome length, and the petiole area can be considered diagnostic traits of $C$. bipinnatus as they did not show differences within and between collected sites. We hypothesize that the low levels of plasticity found in C. bipinnatus across sites is due to the high tolerance of the species to different environmental conditions.
\end{abstract}

Keywords: Macromorphology; Micromorphology; Phenotype; Phenotypic plasticity reproductive character;

Vegetative character

\section{Background}

Species with wide distribution ranges offer the opportunity to explore the evolutionary and ecological factors acting on their phenotypic expression. Usually, these species show local adaptations or an increased phenotypic plasticity, leading to different morphological and physiological characters in response to environmental conditions (Kollmann and Bañuelos 2004). If there is a great

\footnotetext{
*Correspondence: efrain_tovar@uaem.mx

'Departamento de Sistemática y Evolución, Centro de Investigación en Biodiversidad y Conservación, Universidad Autónoma del Estado de Morelos, Av. Universidad 1001, Col. Chamilpa, Cuernavaca, Morelos CP 62209, Mexico Full list of author information is available at the end of the article
}

variability in the abiotic conditions, species with wide distribution ranges may exhibit differential phenotypes that ultimately lead to taxonomic confusion (Ponsie et al. 2009; Semir et al. 2014). In extreme cases, morphological variability within a species may cause the split of one real taxon into two, or it may cause the merging of two real taxa into one species (Kiełtyk and Mirek 2014).

A large quantity of studies employ a morphometric approach of natural populations or herbarium material to solve taxonomic problems due to high levels of intraspecific morphological variability (Conesa et al. 2012; Kiełtyk and Mirek 2014). However, the main disadvantage in using

\section{实}


solely a morphometric approach in natural populations is the difficulty to distinguish between factors that originate the observed variation. Genetic diversity and phenotypic plasticity may contribute importantly to the phenotypic variance observed in natural populations (Schlichting 1986; Nicotra et al. 2010). Unless plants are cultivated in uniform conditions (greenhouse experiments), the relative contribution of these factors is unknown. In order to avoid such constraints of morphometric analysis, several authors combine morphological as well as molecular data to disentangle the taxonomic status of a certain population (e.g., Reed and Frankham 2001; Kuta et al. 2013; Stenøien et al. 2014). However, even when molecular data reveals the genetic structure of populations, these studies are time consuming and they do not provide with sufficient data that permit the identification of a species under field conditions. Additionally, genetic diversity has been found to be a poor predictor of quantitative genetic variability (Reed and Frankham 2001). Moreover, the study of the morphology of a certain taxon in contrasting environmental conditions may permit the identification of morphological diagnostic markers and, thus, avoid potential taxonomic confusions.

Abiotic variables such as water stress, mineral nutrient deficiency, and geographical position may have an effect in the overall plant morphology. For example, latitude is negatively correlated with plant height (Moles et al. 2009), while altitude may have a significant effect in leaf morphology and plant height (Ran et al. 2013; Vitasse et al. 2013). Soil parameters also contribute to different macromorphological character expression in plants. Nitrogen $(\mathrm{N})$ and phosphorous $(\mathrm{P})$ are the two critical limiting elements in plant growth due to their poor availability in the soil. Shifts in availability of these nutrients may lead to changes in root architecture (López-Bucio et al. 2003) and in macromorphological characters (Trubat et al. 2006). Another abiotic factor that greatly limits plant growth and development is water availability. Drought reduces plant growth by affecting several biochemical and physiological processes (Holmgren et al. 2011). As a result, plants under water stress show reduced height measured as stem length (Specht et al. 2001; Zhang et al. 2004; Manivannan et al. 2008) and reduced leaf growth and leaf area (Wullschleger et al. 2005; Manivannan et al. 2008; Farooq et al. 2009), and also, water stress reduces head diameter and yield of achenes in sunflowers (Mozaffari et al. 1996).

Cosmos bipinnatus Cav. (Asteraceae, Coreopsidae) is an herbaceous annual species with a wide distribution range in Mexico. It can be found mainly in the montane regions of the country (Vargas-Amado et al. 2013), where it occupies disturbed sites associated to several vegetation types with contrasting environmental conditions (grasslands, scrubs, Quercus forests and Pinus forests). The stems and leaves of C. bipinnatus are almost glabrous; with the leaves being bipinnate with threadlike segments. The inflorescences usually exhibit purple to pink ligules. However, atypical individuals with white ligules have been recorded. Recently, Paniagua-Ibañez et al. (2014) employed a morphometric approach to propose the intraspecific taxon C. bipinnatus var. albiflorus, where white ligule individuals are included.

In this study, we explored the intraspecific microand macromorphological variability of C. bipinnatus in four different vegetation types in central Mexico (grasslands, scrubs, Quercus forests, and Pinus forests). We searched for significant relations of the measured morphological characters of $C$. bipinnatus with abiotic variables such as altitude and several soil parameters $\left(\mathrm{pH}\right.$, organic matter $[\mathrm{OM}], \mathrm{NH}_{4}, \mathrm{NO}_{3}$, $\mathrm{PO}_{4}$, total $\mathrm{N}$ and total $\mathrm{P}$ content). We hypothesized that the environmental pressure operating at each vegetation type will have a significant effect in the overall morphology of C. bipinnatus. More specifically, we expect that $C$. bipinnatus individuals growing at

Table 1 Sampled populations of Cosmpos bipinnatus in central Mexico

\begin{tabular}{|c|c|c|c|c|c|}
\hline \multirow{2}{*}{$\frac{\text { Vegetation type/locality }}{\text { Grassland }}$} & \multirow[t]{2}{*}{ State } & \multicolumn{2}{|c|}{ Coordinates (UTM) } & \multirow[t]{2}{*}{ Altitude (m) } & \multirow[t]{2}{*}{ Soil type } \\
\hline & & & & & \\
\hline Huehuetoca & Mexico State & 0470736 & 2193770 & 2277 & Vertisol \\
\hline Santa Martha & Mexico State & 0459458 & 2108525 & 2840 & Andisol \\
\hline \multicolumn{6}{|l|}{ Scrub } \\
\hline Botanical Garden & Mexico City & 0479893 & 2135838 & 2324 & Phaeozem \\
\hline Concordia & Mexico State & 0471449 & 2158680 & 2406 & Phaeozem \\
\hline \multicolumn{6}{|l|}{ Pinus forest } \\
\hline Tres Marías & Morelos & 0474982 & 2108707 & 2882 & Andisol \\
\hline San Salvador & Mexico City & 0489057 & 2122730 & 2667 & Phaeozem \\
\hline \multicolumn{6}{|l|}{ Quercus forest } \\
\hline Cerro de la Estrella & Mexico City & 0490294 & 2137729 & 2315 & Phaeozem \\
\hline Parque Ecológico & Mexico City & 0479145 & 2129959 & 2573 & Leptosol \\
\hline
\end{tabular}


Table 2 Micro- and macromorphological characters measured in Cosmos bipinnatus

\begin{tabular}{|c|c|}
\hline Character abbreviation & Character description \\
\hline \multicolumn{2}{|l|}{ Macromorphological } \\
\hline \multicolumn{2}{|l|}{ Vegetative } \\
\hline $\mathrm{TH}$ & Total individual height \\
\hline $\mathrm{H} 1 \mathrm{P}$ & Height to first peduncle \\
\hline Ple & Peduncle length \\
\hline PW & Peduncle width \\
\hline NEP & Number of external phyllary series \\
\hline NIP & Number of internal phyllary series \\
\hline MWL & Maximal width of lamina \\
\hline $\mathrm{TL}$ & Total laminal length \\
\hline$P L$ & Petiole length \\
\hline TLL & Total leaf length \\
\hline MWPe & Maximal width of petiole \\
\hline MVD & Midvein diameter \\
\hline NS & Number of leaf segments \\
\hline FA & Foliar área \\
\hline PA & Petiole área \\
\hline TPL & Total palea length \\
\hline MWP & Maximal width of palea \\
\hline OPW & Outer phyllary series width \\
\hline LOP & Length of outer phyllary series \\
\hline IPW & Inner phyllary series width \\
\hline LIP & Length of inner phyllary series \\
\hline \multicolumn{2}{|l|}{ Reproductive } \\
\hline FW & Fruit width \\
\hline $\mathrm{FL}$ & Fruit length \\
\hline TIW & Total inflorescence width \\
\hline DW & Disk width \\
\hline $\mathbb{H}$ & Inflorescence height \\
\hline LN & Ligule number \\
\hline $\mathrm{CL}$ & Total corolla length of disk floret \\
\hline MWC & Maximal width of disk floret's corolla \\
\hline DFL & Total disk floret length \\
\hline LL & Length of ligule \\
\hline MWLi & Maximal width of ligule \\
\hline $\mathrm{R}$ & Red \\
\hline G & Green \\
\hline B & Blue \\
\hline C & Cian \\
\hline M & Magenta \\
\hline Y & Yellow \\
\hline
\end{tabular}

Table 2 Micro- and macromorphological characters measured in Cosmos bipinnatus (Continued)

\begin{tabular}{|c|c|c|}
\hline \multicolumn{3}{|c|}{ Micromorphological characters } \\
\hline $\operatorname{TrL}$ & Trichome length & $\mu \mathrm{m}$ \\
\hline SI & Stomatal index & no. \\
\hline SL & Stoma length & $\mu \mathrm{m}$ \\
\hline SW & Stoma width & $\mu \mathrm{m}$ \\
\hline
\end{tabular}

$\mathrm{mm}$

no.

no.

$\mathrm{cm}$

$\mathrm{cm}$

$\mathrm{cm}$

$\mathrm{cm}$

$\mathrm{mm}$

$\mathrm{mm}$

no.

$\mathrm{cm}^{2}$

$\mathrm{cm}^{2}$

$\mathrm{mm}$

$\mathrm{mm}$

$\mathrm{mm}$

$\mathrm{mm}$

$\mathrm{mm}$

$\mathrm{mm}$

$\mathrm{mm}$

$\mathrm{mm}$

$\mathrm{mm}$

$\mathrm{mm}$

$\mathrm{mm}$

no.

$\mathrm{mm}$

$\mathrm{mm}$

$\mathrm{mm}$

$\mathrm{mm}$

$\mathrm{mm}$

no.

no.

no.

no.

no.

no. drier and warmer sites (i.e., scrubs and grasslands) will exhibit reduced height and shorter reproductive and vegetative structures compared to individuals growing at wetter and more temperate sites (i.e., Pinus forest and Quercus forest).

\section{Methods}

\section{Study species}

Cosmos bipinnatus Cav. is a composite annual herbaceous species belonging to the tribe Coreopsideae (Funk et al. 2009). This species is usually associated to disturbed sites such as roads and agricultural sites. It usually grows as an herb up to $2 \mathrm{~m}$ tall with erect, almost glabrous, and slightly branched stems. The leaves of $C$. bipinnatus may be sessile or with a winged petiole. The lamina is bipinnated with threadlike segments $5-20 \mathrm{~mm}$ long and $0.5-3 \mathrm{~mm}$ wide with an acuminate apex. The peduncles are up to $30 \mathrm{~cm}$ long and may bear one or two inflorescences. The inflorescences exhibit two series of phyllaries which may be lanceolate to ovate-lanceolated. The ligulated flowers are usually liliac, but pink and white may also occur (Rzedowski and Rzedowski 2001). Recently, Paniagua-Ibañez et al. (2014) used a morphometric approach to distinguish between the white and liliac types of $C$. bipinnatus; the proposed name for the white morph is C. bipinnatus var. albiflorus (Paniagua-Ibañez et al. 2014).

Cosmos bipinnatus is distributed in the montane regions of Mexico, particularly in the The Eje Neovolcánico

Table 3 Mean \pm standard error and two-way ANOVA results for each soil parameter measured in eight localities in central Mexico

\begin{tabular}{lllll}
\hline \multirow{2}{*}{$\begin{array}{l}\text { Soil } \\
\text { parameter }\end{array}$} & \multicolumn{2}{c}{$F$} & Mean \pm s.e. & Units \\
\cline { 2 - 4 } & Locality $($ d.f. $=7)$ & Transect $(d . f .=16)$ & & \\
\hline $\mathrm{pH}$ & $10.60^{* * *}$ & $2.21^{* *}$ & $6.65 \pm 0.05$ & \\
$\mathrm{OM}$ & $17.96^{* * *}$ & $1.65 \mathrm{~ns}$ & $6.02 \pm 0.37$ & $\%$ \\
$\mathrm{NH}_{4}$ & $5.68^{* * *}$ & $1.91^{* *}$ & $15.32 \pm 0.74$ & $\mathrm{ppm}$ \\
$\mathrm{NO}_{3}$ & $3.09^{* * *}$ & $2.13^{* *}$ & $9.92 \pm 0.28$ & $\mathrm{ppm}$ \\
$\mathrm{PO}_{4}$ & $26.77^{* * *}$ & $2.32^{* * *}$ & $2.89 \pm 0.18$ & $\mathrm{ppm}$ \\
$\mathrm{N}_{\mathrm{t}}$ & $11.82^{* * *}$ & $1.65 \mathrm{~ns}$ & $0.41 \pm 0.02$ & $\%$ \\
$P_{\mathrm{t}}$ & $14.13^{* * *}$ & $1.71 \mathrm{~ns}$ & $0.07 \pm 0.01$ & $\%$ \\
\hline
\end{tabular}

ns not significant

${ }^{*} P<0.01,{ }^{* * *} P<0.001$ 
(EN), an orographic system that traverses the central part of the Mexico in an east-west direction (Vargas-Amado et al. 2013). Cosmos bipinnatus may be found at altitudes between 2250 and $2750 \mathrm{~m}$. Due to its complex topography, climates, and geological history, the EN is usually considered a center of diversification of a large number of taxa, including the Asteraceae family (Ramamoorthy et al. 1993, Turner and Nesom 1998, Vargas-Amado et al. 2013). Within EN, C. bipinnatus may be associated to grasslands, scrubs, and temperate forests dominated by Pinus and/or Quercus. Due to the wide distribution range of $C$. bipinnatus, this species exhibit a wide phenotypic variation across its range (Rzedowski and Rzedowski 2001).

\section{Collecting sites and micro- and macromorphometric procedure}

For this study, we chose eight localities where C. bipinnatus was the dominant species (Table 1). We chose two sites where C. bipinnatus is associated with each of the following vegetation types: grassland (Huehuetoca and Santa Martha), scrub (Botanical Garden, Concordia), Pinus forest (Tres Marías, San Salvador), and Quercus forest (Cerro de la Estrella, Parque Ecológico). The study sites present four soil types: Vertisol, Leptosol, Andisol, and Phaeozem (Driessen and Deckers 2001) (Table 1). In each of these sites, three transects of $50 \mathrm{~m}$ were drawn; 10 squares of $1 \mathrm{~m}^{2}$ were marked each $5 \mathrm{~m}$. In each quadrant, we randomly chose one individual of C. bipinnatus with at least three inflorescences and no apparent mechanical damage $(n=60$ individuals per vegetation type).

For the macromorphological measurements, we collected six leaves of each individual. Also, from each of the three inflorescences collected, we chose randomly six of the following structures: ligules, inner phyllaries, outer phyllaries, disk florets, pales, and achenes. Due to the fragility of these structures, these parts where attached by adhesive tape to paper, where the macromorphological characters were measured (Table 2). In addition, to these characters, we also used computer digitalized images of the ligules of each individual in order to quantify their color (parameters cian, magenta, red, blue, yellow). Images were processed with Adobe Photoshop software (Adobe Systems). Macromorphological characters were classified as reproductive or vegetative in accordance to Table 2.

For micromorphological analysis, we selected two leaves per individual. Each leaf was conserved with ethanol $70 \%$. Next, three semipermanent slides of the leaf were done by the replicate technique. These slides were used to determine the types of stoma in C. bipinnatus and the stomatal index (Salisbury 1968). Also, permanent slides of the leaves' epidermis were done. These
Table 4 Mean \pm standard error for each morphological variable measured in eight populations of Cosmos bipinnatus in central Mexico. Nested ANOVA results ( $F$ ) are also shown

\begin{tabular}{|c|c|c|c|}
\hline \multirow{2}{*}{$\begin{array}{l}\text { Morphological } \\
\text { variables }\end{array}$} & \multicolumn{2}{|r|}{$F$} & \multirow[t]{2}{*}{ Mean \pm s.e. } \\
\hline & Locality $($ d.f. $=7)$ & Transect $(d . f .=16)$ & \\
\hline
\end{tabular}

\begin{tabular}{|c|c|c|c|}
\hline \multicolumn{4}{|c|}{ Macromorphological characters } \\
\hline \multicolumn{4}{|c|}{ Vegetative } \\
\hline PLe & $48.82^{* * *}$ & $3.43^{* * *}$ & $152.81 \pm 2.33$ \\
\hline PW & $77.21^{* * *}$ & $9.03^{* * *}$ & $1.31 \pm 0.01$ \\
\hline NEP & $1.17 \mathrm{~ns}$ & $1.63 \mathrm{~ns}$ & $8.01 \pm 0.01$ \\
\hline NIP & $2.55^{*}$ & $2.95^{* * *}$ & $8.01 \pm 0.01$ \\
\hline MWL & $119.42^{* * *}$ & $39.29 * * *$ & $66.19 \pm 0.66$ \\
\hline $\mathrm{TL}$ & $162.35^{* * *}$ & $31.40^{* * *}$ & $83.86 \pm 0.61$ \\
\hline $\mathrm{PL}$ & $32.76^{* * *}$ & $25.16^{* * *}$ & $6.43 \pm 0.07$ \\
\hline TLL & $182.29^{* * *}$ & $39.56^{* * *}$ & $90.67 \pm 0.64$ \\
\hline MWPe & $64.59^{* * *}$ & $35.75^{* * *}$ & $3.12 \pm 0.03$ \\
\hline MVD & $71.99^{* * *}$ & $18.85^{* * *}$ & $1.41 \pm 0.02$ \\
\hline NS & $132.98^{* * *}$ & $30.94^{* * *}$ & $9.41 \pm 0.04$ \\
\hline FA & $177.83^{* * *}$ & $73.75^{* * *}$ & $9.77 \pm 0.18$ \\
\hline PA & $1.84 \mathrm{~ns}$ & $1.51 \mathrm{~ns}$ & $0.14 \pm 0.01$ \\
\hline TPL & $172.36^{* * *}$ & $10.88^{* * *}$ & $8.07 \pm 0.03$ \\
\hline MWP & $204.28^{* * *}$ & $27.60^{* * *}$ & $1.48 \pm 0.01$ \\
\hline OPW & $813.39^{* * *}$ & $35.56^{* * *}$ & $2.72 \pm 0.1$ \\
\hline LOP & $2147.51^{* * *}$ & $65.10^{* * *}$ & $7.95 \pm 0.03$ \\
\hline IPW & $1615.34^{* * *}$ & $66.48^{* * *}$ & $4.02 \pm 0.02$ \\
\hline LIP & $5.94^{* * *}$ & $1.27 \mathrm{~ns}$ & $10.31 \pm 0.25$ \\
\hline \multicolumn{4}{|c|}{ Reproductive } \\
\hline FW & $25.21^{* * *}$ & $17.28^{* * *}$ & $1.43 \pm 0.02$ \\
\hline $\mathrm{FL}$ & $169.80^{* * *}$ & $17.88^{* * *}$ & $7.04 \pm 0.03$ \\
\hline TIW & $230.20^{* * *}$ & $3.47^{* * *}$ & $51.68 \pm 0.5$ \\
\hline DW & $1.01 \mathrm{~ns}$ & $1.00 \mathrm{~ns}$ & $19.56 \pm 9.79$ \\
\hline$\Vdash H$ & $71.78^{* * *}$ & $12.41^{* * *}$ & $10.84 \pm 0.12$ \\
\hline LN & $10.99^{* * *}$ & $8.98^{* * *}$ & $8.07 \pm 0.03$ \\
\hline $\mathrm{CL}$ & $114.91^{* * *}$ & $72.34^{* * *}$ & $5.34 \pm 0.02$ \\
\hline MWC & $25.21^{* * *}$ & $17.28^{* * *}$ & $1.43 \pm 0.02$ \\
\hline DFL & $169.80^{* * *}$ & $17.88^{* * *}$ & $7.04 \pm 0.03$ \\
\hline LL & $1741.35^{* * *}$ & $18.78^{* * *}$ & $28.53 \pm 0.11$ \\
\hline MWLi & $2857.95^{* * *}$ & $67.06^{* * *}$ & $14.85 \pm 0.07$ \\
\hline \multicolumn{4}{|c|}{ Micromorphological characters } \\
\hline $\operatorname{TrL}$ & $1.61 \mathrm{~ns}$ & $2.27 \mathrm{~ns}$ & $111.72 \pm 2.01$ \\
\hline $\mathrm{SI}$ & $7.60^{* * *}$ & $0.07 \mathrm{~ns}$ & $76.85 \pm 1.17$ \\
\hline SL & $13.92^{* * *}$ & $3.71^{* * *}$ & $30.16 \pm 0.25$ \\
\hline SW & $12.71^{* * *}$ & $6.27^{* * *}$ & $20.64 \pm 0.22$ \\
\hline
\end{tabular}

ns not significant

${ }^{*} P<0.05,{ }^{* *} P<0.01,{ }^{* *} P<0.001$ 
slides were analyzed by high vacuum scanning electron microscopy (HVSEM) and by differential interference contrast microscopy (DICM). We used these slides to characterize the trichomes and papillae present in $C$. bipinnatus.

\section{Soil analysis}

In order to characterize the soil, we systematically collected four soil samples along a transect of $40 \mathrm{~m}$ (we collected a sample each $10 \mathrm{~m}$ ). For the soil analysis, we weighted $200 \mathrm{~g}$ of dry soil which was previously sieved with a 2-mm mesh. For each sample, we quantified the following variables: $\mathrm{pH}$, content of organic matter (MO; measured with a Total Organic Carbon Analyzer, the $\mathrm{CO}_{2}$ carbon released during the combustion was measured by Non-Dispersive Infrared Detection), ammonium content $\left(\mathrm{NH}_{4}\right.$; quantified after a extraction with $\mathrm{KCl})$, nitrate content $\left(\mathrm{NO}_{3} ;\right.$ quantified through ion

Table 5 Regression analysis between morphological variables measured in Cosmos bipinnatus and abiotic variables in central Mexico. Only variables with significant correlations $(P<0.05)$ are shown

\begin{tabular}{|c|c|c|c|c|c|c|c|c|c|c|c|c|c|c|c|c|}
\hline \multirow{2}{*}{$\begin{array}{l}\text { Morphological } \\
\text { character }\end{array}$} & \multicolumn{2}{|c|}{ Altitude } & \multicolumn{2}{|l|}{$\mathrm{NH}_{4}$} & \multicolumn{2}{|l|}{$\mathrm{PO}_{4}$} & \multicolumn{2}{|l|}{$P_{\mathrm{t}}$} & \multicolumn{2}{|l|}{$\mathrm{pH}$} & \multicolumn{2}{|l|}{$\mathrm{OM}$} & \multicolumn{2}{|l|}{$N_{\mathrm{t}}$} & \multicolumn{2}{|l|}{$\mathrm{NO}_{3}$} \\
\hline & $\bar{R}$ & $R^{2}$ & $\bar{R}$ & $R^{2}$ & $\bar{R}$ & $R^{2}$ & $\bar{R}$ & $R^{2}$ & $\bar{R}$ & $R^{2}$ & $\bar{R}$ & $R^{2}$ & $\bar{R}$ & $R^{2}$ & $\bar{R}$ & $R^{2}$ \\
\hline \multicolumn{17}{|c|}{ Macromorphological characters } \\
\hline \multicolumn{17}{|l|}{ Vegetative } \\
\hline $\mathrm{TH}$ & -0.45 & 0.20 & - & - & - & - & - & - & - & - & - & - & - & - & - & - \\
\hline $\mathrm{H} 1 \mathrm{P}$ & -0.67 & 0.44 & 0.44 & 0.19 & - & - & - & - & - & - & - & - & - & - & - & - \\
\hline Ple & - & - & - & - & - & - & - & - & - & - & 0.67 & 0.45 & 0.44 & 0.19 & - & - \\
\hline PW & 0.74 & 0.55 & -0.51 & 0.26 & - & - & 0.69 & 0.47 & - & - & - & - & - & - & - & - \\
\hline MWL & & & 0.45 & 0.20 & 0.43 & 0.18 & - & - & - & - & - & - & - & - & - & - \\
\hline $\mathrm{TL}$ & -0.46 & 0.21 & 0.43 & 0.18 & - & - & - & - & - & - & - & - & - & - & - & - \\
\hline TLL & -0.46 & 0.21 & 0.42 & 0.18 & - & - & - & - & - & - & - & - & - & - & - & - \\
\hline MWPe & 0.45 & 0.20 & - & - & - & - & - & - & - & - & - & - & - & - & - & - \\
\hline MVD & - & - & - & - & - & - & -0.52 & 0.26 & - & - & -0.54 & 0.28 & -0.42 & 0.17 & - & - \\
\hline PA & - & - & -0.41 & 0.16 & - & - & - & - & - & - & - & - & - & - & - & - \\
\hline TPL & -0.56 & 0.31 & - & - & 0.68 & 0.46 & - & - & 0.42 & 0.18 & - & - & -0.55 & 0.30 & - & - \\
\hline MWP & -0.57 & 0.32 & 0.59 & 0.34 & 0.52 & 0.27 & - & - & - & - & - & - & - & - & - & - \\
\hline OPW & - & - & & & 0.41 & 0.17 & 0.49 & 0.24 & - & - & 0.49 & 0.24 & - & - & - & - \\
\hline LOP & - & - & 0.53 & 0.28 & 0.49 & 0.24 & 0.59 & 0.34 & - & - & 0.56 & 0.31 & - & - & - & - \\
\hline IPW & - & - & 0.46 & 0.21 & 0.47 & 0.22 & 0.41 & 0.16 & - & - & - & - & - & - & - & - \\
\hline LIP & - & - & - & - & 0.73 & 0.53 & - & - & - & - & - & - & - & - & - & - \\
\hline \multicolumn{17}{|l|}{ Reproductive } \\
\hline TIW & - & - & - & - & 0.52 & 0.28 & 0.41 & 0.16 & - & - & - & - & - & - & - & - \\
\hline DW & - & - & -0.41 & 0.16 & - & - & - & - & - & - & - & - & - & - & - & - \\
\hline $\mathbb{H}$ & - & - & 0.42 & 0.18 & -0.45 & 0.21 & - & - & - & - & - & - & - & - & -0.56 & -0.31 \\
\hline DFL & - & - & - & - & 0.62 & 0.39 & - & - & - & - & - & - & - & - & - & - \\
\hline $\mathrm{LL}$ & - & - & 0.41 & 0.17 & 0.53 & 0.28 & - & - & - & - & - & - & - & - & - & - \\
\hline MWLi & - & - & 0.46 & 0.21 & 0.50 & 0.25 & 0.43 & 0.19 & - & - & 0.45 & 0.16 & - & - & - & - \\
\hline $\mathrm{R}$ & -0.52 & 0.27 & - & - & 0.48 & 0.23 & - & - & 0.56 & 0.32 & - & - & - & - & - & - \\
\hline G & -0.49 & 0.23 & - & - & - & - & - & - & 0.56 & 0.31 & - & - & - & - & - & - \\
\hline B & - & - & - & - & - & - & - & - & 0.58 & 0.34 & - & - & - & - & - & - \\
\hline C & 0.49 & 0.24 & - & - & -0.48 & 0.23 & - & - & -0.51 & 0.26 & - & - & - & - & - & - \\
\hline M & 0.42 & 0.17 & - & - & - & - & - & - & -0.46 & 0.21 & - & - & - & - & - & - \\
\hline \multicolumn{17}{|c|}{ Micromorphological characters } \\
\hline $\mathrm{SI}$ & - & - & -0.42 & 0.17 & - & - & -0.47 & 0.21 & - & - & -0.46 & 0.21 & - & - & - & - \\
\hline SL & 0.55 & 0.30 & - & - & - & - & - & - & - & - & - & - & - & - & - & - \\
\hline
\end{tabular}

DF discriminant function 
capillary electrophoresis), phosphate content $\left(\mathrm{PO}_{4}\right)$, total nitrogen content $\left(N_{\mathrm{t}}\right.$; following the method of Bremmer (1965)) and total phosphorous $\left(P_{t}\right.$; measured through the method developed by Bray and Kurtz (1945); Table 3).

\section{Data analyses}

In order to determine the effect of collecting site (locality), transect and individual on the micro- and macromorphological characters measured in C. bipinnatus, we conducted nested Analysis of Variance (ANOVA). Individuals were nested within transect, and the latter within collecting site. All discontinuous data were transformed as [(x) $1 / 2+0.5]$ (Zar 2010). We conducted two-way ANOVA to determine the effect of collecting site and transect on the soil parameters measured. Also, regression analyses were performed between altitude and the soil parameters measured.

Then, to determine the relation between the abiotic variables (altitude, soil parameters) and the morphology of $C$. bipinnatus, we conducted regression analysis between these data sets. Discriminant function analysis (DFA) was used to determine how macromorphological characters separate individuals into groups. We establish vegetation type as the predictor variable of the groups. For DFA, we excluded the variables that showed correlation coefficients $>0.6$ in order to improve the performance of the analysis. Also, we performed linear regression analyses with vegetation type as independent variable and the morphological characters as dependent variables. For this analysis, we rank vegetation types along an environmental gradient according to increasing water availability and decreasing temperature (Scrub-Grassland-Quercus forest-Pinus forest).

For each character measured, we calculated the Simplified Relative Distance Plasticity Index $\left(\mathrm{RDPI}_{\mathrm{s}}\right.$; Valladares et al. 2006). The RDPI measures the relative distances between the mean values of the chosen characters measured for all pairwise comparisons of vegetation types. The values of $\mathrm{RDPI}_{\mathrm{s}}$ range from 0 (no plasticity) to 1 (maximal plasticity). For more details of calculation of $\mathrm{RDPI}_{\mathrm{s}}$ revise Valladares et al. (2006).

Finally, to determine the intercorrelation within vegetative and reproductive characters, the Pearson product moment correlation was computed between both data sets. JMP software version 11 (SAS Institute, Cary, NC) was used for all statistical analyses.

\section{Results}

Nested ANOVA revealed a significant effect of collecting site (locality) in all macromorphological vegetative (except for number of external phyllary series and petiole area) and reproductive characters (except disk width), as well as micromorphological characters (except trichome length; Table 4). Transect had a significant effect in all macromorphological vegetative (except number of external phyllary series, petiole area and length of inner phyllary series) and reproductive characters (except disk width). Also, transect had an effect in all but two (trichome length and stomatal index) micromorphological characters. In a similar fashion, locality had a significant effect in all soil parameters measured, while locality had a significant effect in all but three $\left(\mathrm{OM}, N_{\mathrm{t}}\right.$, and $\left.P_{\mathrm{t}}\right)$ soil parameters (Table 3). However, altitude did not have a significant effect on any soil parameter, except for $\mathrm{NH}_{4}$ content, which exhibited a negative correlation with altitude $\left(R^{2}=0.29, R=-0.54, P<0.05\right)$.

Regression analyses showed that $71.43 \%$ of the morphological characters measured in C. bipinnatus had an effect with at least one of the abiotic variables (altitude and soil parameters) considered in this study (Table 5). Five vegetative characters, five reproductive characters, and two micromorphological characters did not have a significant effect with any of the abiotic variables. The remainder characters were significantly related with at least one abiotic variable (Table 5). No obvious patterns

Table 6 Standardized canonical discriminant function coefficients of morphological variables measured in Cosmos bipinnatus in eight populations in central Mexico

\begin{tabular}{|c|c|c|}
\hline Morphological variable & DF1 & DF2 \\
\hline TH & -0.49 & 0.28 \\
\hline $\mathrm{H} 1 \mathrm{P}$ & 0.14 & 0.01 \\
\hline Ple & 0.15 & 0.32 \\
\hline PW & 0.26 & -0.69 \\
\hline NEP & 0.06 & 0.02 \\
\hline NIP & 0.07 & -0.03 \\
\hline MWL & -0.14 & 0.39 \\
\hline$P L$ & 0.04 & -0.08 \\
\hline MWPe & 0.36 & -0.23 \\
\hline NS & -0.40 & 0.23 \\
\hline PA & 0.03 & 0.01 \\
\hline TPL & -0.02 & 0.34 \\
\hline MWP & 0.14 & -0.15 \\
\hline LIP & 0.16 & 0.17 \\
\hline FW & -0.10 & -0.33 \\
\hline $\mathrm{FL}$ & -0.57 & -0.39 \\
\hline DW & 0.58 & 0.18 \\
\hline $\mathbb{H}$ & 0.29 & 0.09 \\
\hline LN & 0.05 & -0.10 \\
\hline $\mathrm{CL}$ & 0.09 & 0.06 \\
\hline MWC & 0.17 & 0.13 \\
\hline Y & -0.06 & -0.24 \\
\hline Eigenvalue & 2.67 & 1.93 \\
\hline Percent variation & 52.98 & 38.25 \\
\hline
\end{tabular}


arise from these analyses. However, it is interesting to outline the relation between $\mathrm{PO}_{4}$ content and palea and phyllary-related characters. Soil $\mathrm{pH}$ had a significant effect in all characters related with ligule color. Altitude and $\mathrm{PO}_{4}$ also had an effect in ligule color (Table 5). Finally, $\mathrm{NH}_{4}$ content was significantly related with the length and width of leaves, paleae, and ligules. It is noteworthy that the vast majority ( $92.30 \%$ ) of the values of $R^{2}<0.35$ (Table 5).

DFA with vegetation type as the grouping variable generated two significant discriminant functions (DF) that explained $91.23 \%$ of the variation in the original data set. Length variables of disk, fruit, and total individual height had the highest standardized canonical discriminant function coefficients in DF1, while the width of lamina, paleae, and peduncle length and the maximal width of lamina showed the highest discriminant function coefficients in DF2 (Table 6). A plot of canonical scores of DF2 vs DF1 was generated (Fig. 1). In general, C. bipinnatus individuals collected at grasslands and Pinus forests show almost no overlap with individuals collected at another vegetation type. However, indivduals collected at scrubs and Quercus forests show extensive overlap in the ordination space (Fig. 1).

Regression analyses with vegetation type as independent variable and all morphological characters as dependent variables revealed that $44 \%$ of the characters were affected by the environmental gradient (scrub-grassland-Quercus forest-Pinus forest) total individual height and leaf size-related characters decreased along the environmental gradient. In contrast, reproductive characters tend to increase along the gradient. In particular, ligule characters and floral characters were affected by the environmental gradient. Also, the length and width of stomata increased along the environmental gradient (Table 7).

The $\mathrm{RDPI}_{\mathrm{s}}$ showed that the morphological characters measured in C. bipinnatus showed low plasticity values across sites. Only $6.97 \%$ of all characters showed plasticity values above 0.2 , while $44.18 \%$ of the characters showed plasticity values close to zero $(<0.9$; Table 8$)$.

A matrix of pairwise correlation between macromorphological characters is shown in Additional file 1. All characters showed correlation with at least one character. We found that ligule, bract, foliar, and phyllary sizerelated characters showed massive correlations within themselves. Particularly, ligule width and ligule length were correlated with 76.31 and $68.42 \%$ of the characters, respectively. On the other hand, ligule number was correlated with only $8 \%$ of the characters. Fruit width showed correlation with only $18.42 \%$ of the characters. Finally, characters related with ligule color showed an overall low percentage of correlations with other characters (Additional file 1).

Finally, permanent slides analyzed through HVSM and DICM revealed the presence of simple uniseriated trhicomes in the leaf epidermis of C. bipinnatus. Also, papillae

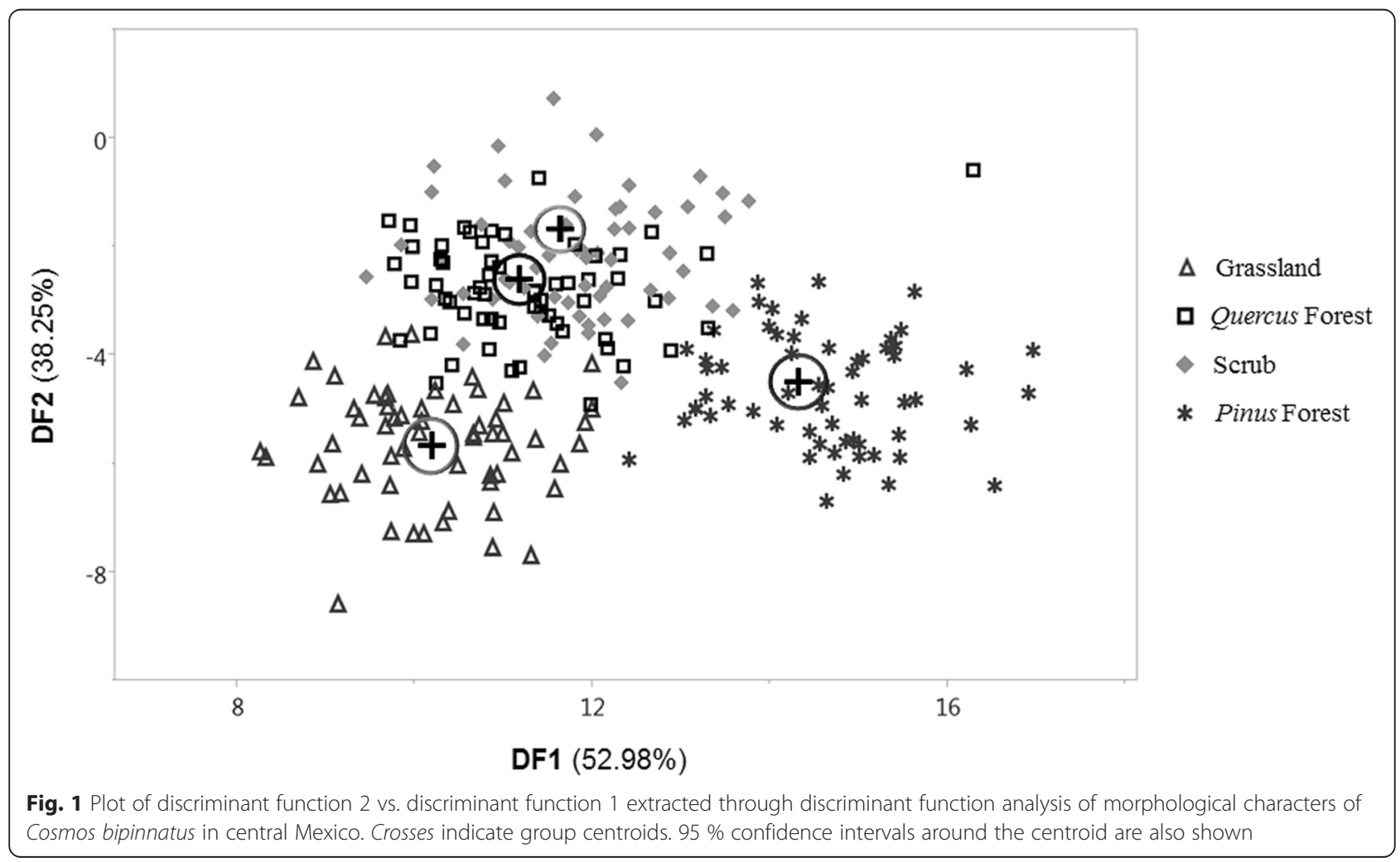


Table 7 Effect of the environmental gradient (scrub-grassland -Quercus forest_-Pinus forest) on morphological characters revealed by regression analysis. Only morphological variables with significant relations with the environmental gradients are shown $(P<0.05)$. For character description refer to Table 2

\begin{tabular}{|c|c|c|c|}
\hline Character & $R^{2}$ & $R$ & $F_{(3238)}$ \\
\hline \multicolumn{4}{|c|}{ Macromorphological vegetative } \\
\hline $\mathrm{TH}$ & 0.18 & -0.42 & 54.62 \\
\hline PW & 0.13 & 0.36 & 36.77 \\
\hline TL & 0.10 & -0.32 & 26.93 \\
\hline TLL & 0.09 & -0.30 & 24.17 \\
\hline OPW & 0.10 & 0.32 & 28.78 \\
\hline LOP & 0.06 & 0.24 & 16.28 \\
\hline IPW & 0.15 & 0.39 & 43.82 \\
\hline \multicolumn{4}{|c|}{ Macromorphological reproductive } \\
\hline FW & 0.02 & 0.14 & 6.89 \\
\hline TIW & 0.19 & 0.44 & 58.91 \\
\hline DW & 0.17 & 0.41 & 51.88 \\
\hline 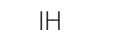 & 0.05 & 0.22 & 14.96 \\
\hline $\mathrm{CL}$ & 0.10 & 0.32 & 27.08 \\
\hline MWC & 0.07 & 0.26 & 18.05 \\
\hline DFL & 0.13 & 0.36 & 36.54 \\
\hline LL & 0.14 & 0.37 & 39.5 \\
\hline MWLi & 0.11 & 0.33 & 30.21 \\
\hline C & 0.11 & 0.33 & 31.49 \\
\hline \multicolumn{4}{|c|}{ Micromorphological } \\
\hline$S L$ & 0.11 & 0.33 & 5.99 \\
\hline SW & 0.10 & 0.32 & 5.23 \\
\hline
\end{tabular}

were found in the leaf margins as well as in the secondary veins, while stomata were also present (Fig. 2). Two types of stomata were found: anisocytic and anomocytic.

\section{Discussion}

Species with wide distribution ranges usually exhibit broad morphological variability. Abiotic variables may have a significant effect on the phenotype of a species. As a consequence, assessing morphological variability in widespread species often brings taxonomic confusion, due to the wide array of phenotypes that taxa may exhibit (Geng et al. 2006; Conesa et al. 2012; Kiełtyk and Mirek 2014; Paniagua-Ibañez et al. 2014). In this study, we assessed the morphological variability of C. bipinnatus under field conditions and its relation to abiotic conditions (altitude and soil parameters).

The analyses performed in this study revealed that 40 out of 43 characters had a significant effect on vegetation type and transect as revealed by nested ANOVA results (Table 4). This finding reveals that C. bipinnatus shows a broad morphological variation. This result is in accordance with previous taxonomic work (e.g., Rzedowski and Rzedowski 2001). Despite the great morphological variability shown by $C$. bipinnatus, we were able to identify some characters that may be considered as diagnostic traits. The number of external phyllaries, trichome length, and petiole area did not show a significant effect of locality and transect as revealed by ANOVA. These characters show low dispersion values, and thus, we propose that these can be employed as species diagnostic morphological characters (Table 4).

Although we found high morphological variability of C. bipinnatus, the RDPI $\mathrm{I}_{\mathrm{s}}$ across all sites showed that almost all characters showed plasticity values close to zero (Table 8). We explain these findings with the following argument. Cosmos bipinnatus is a species associated to human-disturbed sites (e.g., roadsides, agricultural sites) and early succession stages (Rzedowski and Rzedowski 2001; Vargas-Amado et al. 2013). As such, these species often exhibit a high tolerance to adverse conditions such as high solar exposure and drought (Hobbs and Huenneke 1992; Andraski and Bundy 2003), exhibiting physiological adaptations to these particular conditions (Caplan and Yeakley 2013). So, we hypothesize that the populations of C. bipinnatus sampled in this study are not in severe physiological stress, resulting in low values of phenotypic plasticity across all sites. Previous studies have demonstrated that agricultural habitats and human-disturbed habitats are heterogeneous habitats regarding nutrient availability, leading to population differentiation and ultimately leading to contrasting morphologies within sites (Leiss and Müller-Schärer 2001). Thus, the heterogeneity of the environmental conditions on a small spatial scale (within sites and transects) could be the main source of phenotypic variation for C. bipinnatus. In order to test this hypothesis, future studies should obtain pure lines of C. bipinnatus and perform reciprocal transplants in contrasting environments in order to evaluate precisely the contribution of phenotypic plasticity in this species.

\section{Differential morphological expression of $C$. bipinnatus under different vegetation types}

We expected that individuals growing at scrubs and grasslands would exhibit a smaller height with small reproductive and vegetative structures compared with individuals growing at Quercus forests and Pinus forests. Interestingly, we found the opposite pattern in some vegetative characters. In particular, individuals which tend to be smaller with shorter leaves were present at Quercus and Pinus forest compared with C. bipinnatus individuals growing at scrubs and grasslands. However, all reproductive characters (flower-size-related characters) showed an increase in size along the environmental 
Table 8 Simplified Relative Distance Plasticity Index $\left(\mathrm{RDPI}_{\mathrm{s}}\right.$ ) across all sites for all macro- and micromorphological characters measured of C. bipinnatus in Central Mexico

\begin{tabular}{|c|c|}
\hline Character abbreviation & $\mathrm{RDPI}_{\mathrm{s}}$ \\
\hline \multicolumn{2}{|l|}{ Macromorphological } \\
\hline \multicolumn{2}{|l|}{ Vegetative } \\
\hline $\mathrm{TH}$ & 0.43 \\
\hline $\mathrm{H} 1 \mathrm{P}$ & 0.23 \\
\hline PLe & 0.16 \\
\hline PW & 0.15 \\
\hline NEP & 0.00 \\
\hline NIP & 0.00 \\
\hline MWL & 0.15 \\
\hline $\mathrm{TL}$ & 0.12 \\
\hline$P L$ & 0.06 \\
\hline TLL & 0.12 \\
\hline MWP & 0.08 \\
\hline MVD & 0.05 \\
\hline NS & 0.03 \\
\hline FA & 0.16 \\
\hline PA & 0.08 \\
\hline TPL & 0.05 \\
\hline MWP & 0.03 \\
\hline OPW & 0.12 \\
\hline LOP & 0.15 \\
\hline IPW & 0.14 \\
\hline LIP & 0.12 \\
\hline \multicolumn{2}{|l|}{ Reproductive } \\
\hline FW & 0.06 \\
\hline $\mathrm{FL}$ & 0.11 \\
\hline TIW & 0.19 \\
\hline DW & 0.13 \\
\hline $\mathbb{H}$ & 0.10 \\
\hline LN & 0.00 \\
\hline $\mathrm{CL}$ & 0.08 \\
\hline MWC & 0.15 \\
\hline DFL & 0.10 \\
\hline LL & 0.19 \\
\hline MWLi & 0.24 \\
\hline $\mathrm{R}$ & 0.02 \\
\hline G & 0.02 \\
\hline B & 0.00 \\
\hline C & 0.11 \\
\hline M & 0.03 \\
\hline$Y$ & 0.05 \\
\hline
\end{tabular}

Table 8 Simplified Relative Distance Plasticity Index (RDPI $)$ across all sites for all macro- and micromorphological characters measured of C. bipinnatus in Central Mexico (Continued)

\begin{tabular}{ll}
\hline Micromorphological characters & \\
TrL & 0.04 \\
SI & 0.05 \\
SL & 0.05 \\
SW & 0.06 \\
\hline
\end{tabular}

gradient. Also, size-related stomata characters also increased following the environmental gradient (Table 7).

Quercus and Pinus forests usually exhibit a greater water and nutrient availability compared with grasslands and scrubs in central Mexico. Thus, we expected an overall increase in size along the environmental gradient. The finding of the inverse pattern in some vegetative characters suggests that resource allocation towards vegetative characters is greater at grasslands and scrubs. Meanwhile, resource allocation in Pinus forests and Quercus forests favors an increase in size of reproductive structures (measured as flower-size-related characters). As C. bipinnatus is an annual herb, this strategy seems advantageous. In favorable sites, more nutrients will be available and the production of pollen and seeds would be enhanced, while at adverse conditions the production of higher plants with larger leaves would favor the photosynthetic activity of C. bipinnatus.

On the other hand, discriminant function analysis (DFA) revealed that individuals of $C$. bipinnatus collected at grasslands and Pinus forests were grouped into two distinct clusters, while individuals growing at scrubs and Quercus forests showed significant overlap (Fig. 1). The differences between the environmental conditions between grasslands and Pinus forests may act as an environmental pressure that leads to contrasting phenotypic expression of C. bipinnatus.

DFA also showed that individuals collected at scrubs and Quercus forest exhibited significant overlap (Fig. 1). Following the above argument, this pattern may arise because local conditions are very similar between sites. We hypothesize that the similarity in the environmental conditions between the sampled Quercus forests and scrubs may explain the observed pattern. In central Mexico, some Quercus forests (dominated by Quercus deserticola and Quercus frutex among others) are often associated with water-stress conditions similar to those found in scrubs (Medina Lemus and Tejero-Díez 2006). Also, severe deforestation in the last century in central Mexico has led to the establishment of shrub- or scrub-type vegetation in sites previously occupied by Quercus or other tree species (Rzedowski 1978; Challenger 1998; Galicia and García-Romero 2007). In particular, in one scrub locality sampled in this study (Concordia), we found several 

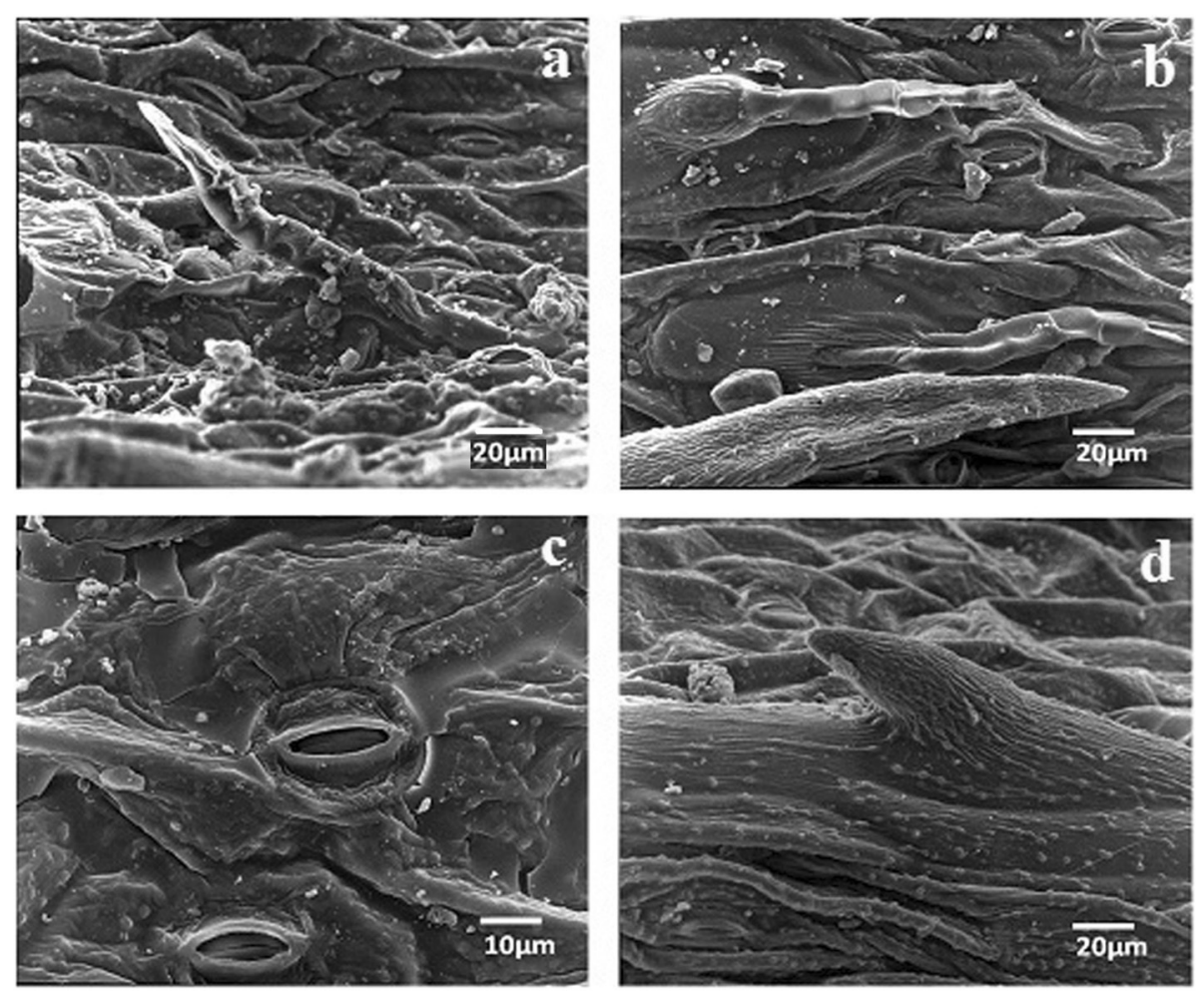

Fig. 2 Trichomes (a, b), stomata (c), and papillae (d) in leaf epidermis of C. bipinnatus revealed by high vacuum scanning electron microscopy. See text for details

sparsely Quercus sp. individuals in poor condition, suggesting that this site was formerly a Quercus forest (Medina Lemus and Tejero-Díez 2006). Thus, the similarity in the conditions between the Scrub and Quercus forest sampled in this study and the recent deforestation of Quercus forests may account for the overlap of C. bipinnatus individuals revealed by DFA.

\section{Abiotic variables and character expression of $C$. bipinnatus}

We found a significant effect of locality in all soil parameters measured (Table 3 ). Also, locality showed a significant effect in all but three micro- and macromorphological characters of $C$. bipinnatus (Table 4). Regression analysis between morphological and abiotic variables revealed some interesting patterns. We are aware that relatively low determination coefficients were obtained through the regression analyses. That is, variables not considered in this study (i.e., genetic) may also have a significant effect in morphological expression in C. bipinnatus. However, we briefly discuss the general patterns deduced in this study.

First, a negative correlation was found between total individual height and altitude $(r=-0.45)$. This pattern may arise because altitude has a significant effect in precipitation and temperature (Dillion et al. 2006). Reduced temperatures and shifts in precipitation may account for the observed pattern in height of $C$. bipinnatus. Smaller plants at high altitudes may also occur in response to $\mathrm{NH}_{4}$ content. In this study altitude was negatively correlated with soil $\mathrm{NH}_{4}$ content $(r=-0.54)$. As nitrogen is a macronutrient found in proteins and nucleic acids, the increase in altitude will reduce the nitrogen available to the plant, leading to smaller plants. This pattern is coincident with other studies reporting smaller plants at increasing altitudes (Lavorel and Grigulis 2012). Besides the effect of soil $\mathrm{NH}_{4}$ content in plant height, we found that this soil parameter was also significantly correlated with the overall size characters related with leaves, ligules, and paleae (Table 5). The role of $\mathrm{NH}_{4}$ in plant nutrition may also account for this pattern.

Another pattern found between abiotic variables and the morphology of $C$. bipinnatus is the relation between ligule colors and $\mathrm{pH}$. Interestingly, all color characters were related with soil acidity (Table 5 ). At greater soil acidity there is a trend for ligules to exhibit predominantly cian and magenta colors (i.e., white), while at alkaline soils red, blue, and green will be the predominant colors (i.e., purple). This pattern may be partially explained by the differential colors that anthocyanins may exhibit when subjected to different $\mathrm{pH}$ levels (Bueno et al. 2012). These pigments are water soluble and exhibit a red coloration 
when subjected acid solutions, purple in near neutral $\mathrm{pH}$ and blue in alkaline solutions (Bueno et al. 2012). Thus, soil $\mathrm{pH}$ may be partially involved in ligule pigmentation. However, genetic factors may greatly contribute to ligule color. As mentioned earlier, Paniagua-Ibañez et al. (2014) proposed the intraspecific taxa C. bipinnatus var. albiflorus where white ligule individuals are included. Individuals of C. bipinnatus var. albiflorus were found in close proximity to $C$. bipinnatus with purple ligules. The soil $\mathrm{pH}$ of the locality where both taxa were found was nearly neutral ( $\mathrm{pH}=7.07)$. So, we hypothesize that ligule color is under genetic control, while soil $\mathrm{pH}$ may be playing a minor role.

In addition to soil $\mathrm{pH}$ and $\mathrm{NH}_{4}$ content, $\mathrm{PO}_{4}$ content in soil also had a significant effect in a number of characters. In particular, $\mathrm{PO}_{4}$ showed a positive significant effect in several reproductive characters related with the overall size of ligules and inflorescences. Also, vegetative characters such as the size of phyllaries were positively and significantly correlated to soil's $\mathrm{PO}_{4}$ content (Table 5). Phosphorous is considered one of the most important nutrients in terrestrial ecosystems (Donahue et al. 1997) and is considered a macronutrient in plants. As such, the lowered levels of phosphorous have been related with a diminished production of flowers and leaves as well as poor performance of plants (Marschner 2002; Agusti 2003; Lavorel and Grigulis 2012).

\section{Character correlation in C. bipinnatus}

Morphological character correlation is a well-known feature of plants (Price and Weitz 2012). However, the study of character correlation in a particular taxon is important, as this will facilitate the selection of characters in a morphological study: the characters that exhibit more independence would be the ideal ones to be included in morphological analysis.

For C. bipinnatus, we found massive character correlation; all macromorphological characters were correlated with at least one character (Additional file 1). This raises an interesting question regarding morphometric studies: which characters should we employ in the data analysis? In this particular case, we employed a DFA analysis to discriminate between individuals growing at different vegetation types. DF1 clearly separated individuals into groups (Fig. 1). Variables total individual height (TH), number of leaf segments (NS), fruit length (FL), and disk width (DW) had the highest standardized canonical discriminant function coefficients in DF1 were. These variables should be assessed when comparing the overall morphology of $C$. bipinnatus growing at different vegetation types.

However, when assessing the morphological variability of C. bipinnatus within a population, other characters should be employed. As suggested by some authors (e.g.,
Tetsana et al. 2014), we recommend that characters exhibiting massive intercorrelation should be omitted of morphological analyses. In the case of $C$. bipinnatus, we found that all characters exhibited correlation with at least one character. However, leaf, ligule, and bract size-related characters showed high and significant correlations within themselves. Thus, a limited number of size-related characters of these structures should be employed in this kind of studies (i.e., only one length measurement). Also, the length and width of ligules should be avoided, as these showed correlations with $68-76 \%$ of the characters. On the other hand, some characters clearly exhibited low correlations. In particular, the number of ligules and the fruit width showed low percentage of correlations with other characters. Also, characters regarding ligule colors showed almost no correlations with other vegetative characters. So, we suggest that these characters may be helpful in morphological studies of $C$. bipinnatus and in members of the Asteraceae family in general.

\section{Conclusions}

In this study we explored the intraspecific morphological variability of Cosmos bipinnatus. The results obtained in these study revealed that this species shows a broad range of morphological variation partly due to the environmental pressure acting at each site (e.g. altitude and $\mathrm{NH}_{4}$ content). Despite its great morphological variability, we were able to identify diagnostic morphological characters for Cosmos bipinnatus: number of external phyllaries, trichome length and petiole area. We propose that these characters should be explored in detail when taxonomic confusion arises. Also, massive character intercorrelation was found in the morphological characters of this species. Although this was an expected result, we found that flower-related characters (number of ligules, fruit width and ligule color) showed low intercorrelation and thus, they should be employed in morphometric studies of Cosmos bipinnatus and other members of the Asteraceae family.

We hypothesize that individuals growing at wetter and more temperate habitats (Pinus and Quercus forest) will display greater height and longer structures compared to drier and warmer habitats (Scrub and Grasslands). Regarding reproductive structures, we found bigger flowers and associated structures in temperate habitats. However, the opposite pattern was found when we explored vegetative characters. The differential resource allocation between sites may partly explain this pattern.

Finally we found low levels of phenotypic plasticity in all characters analyzed. As a weedy species, C. bipinnatus shows high tolerance to environmental stress. So, we hypothesize that the plants collected at contrasting vegetation types were not in severe physiological stress. Also, we propose that the heterogeneity of the environmental 
conditions on small spatial scales is the main source of phenotypic variation of C. bipinnatus. However, future studies should explore the phenotypic plasticity in more detail by performing reciprocal transplants of pure lines growing at contrasting environments in order to evaluate precisely the contribution of the phenotypic plasticity to the phenotypic variation of C. bipinnatus.

\section{Additional file}

Additional file 1: Character intercorrelation within and between vegetative and reproductive macromorphological characters of Cosmos bipinnatus. Only significant correlation coefficients $(P<0.05)$ are shown. (XLS 52.0 KB)

\section{Competing interests}

The authors declare that they have no competing interests.

\section{Authors' contributions}

MG contributed with the micromorphological analyses and revision of the manuscript. $\mathrm{OH}$ and SS contributed with the edaphological analyses and revision of the manuscript. PI contributed with the field sampling and experimental work. LC contributed with the statistical analyses and manuscript writing. RR contributed with the taxonomical determination and field work. TS contributed with the original idea, experimental design, statistical analyses and manuscript writing. All authors participated in the review topic design, in the data analyses, and in the manuscript writing. Also, all authors read and approved the final version of the manuscript.

\section{Acknowledgements}

The authors thank Gabriel Flores, Mauricio Mora-Jarvio, and Guillermo Sánchez for their help with field collections and for their technical assistance. This research was supported by grants from CONACYT- Mexico (61725) to E.T.S. Also this research was supported by scholarship from CONACYT-SEP Mexico to M.P.I. We also thank Posgrado en Ciencias Biológicas (UNAM)

\section{Author details}

'Departamento de Sistemática y Evolución, Centro de Investigación en Biodiversidad y Conservación, Universidad Autónoma del Estado de Morelos, Av. Universidad 1001, Col. Chamilpa, Cuernavaca, Morelos CP 62209, Mexico. ${ }^{2}$ Posgrado en Ciencias Biológicas, Universidad Nacional Autónoma de México, Apartado Postal 70-181, 04510 Delegación Coyoacán, DF, México. ${ }^{3}$ Laboratorio de Investigaciones Ambientales, Centro de Investigación en Biotecnología, Universidad Autónoma del Estado de Morelos, Av. Universidad 1001, Col. Chamilpa, Cuernavaca, Morelos CP 62209, Mexico.

Received: 20 March 2015 Accepted: 5 August 2015

Published online: 18 August 2015

\section{References}

Agusti M (2003) Citricultura. Ediciones Mundi Prensa, Madrid

Andraski TW, Bundy LG (2003) Relationships between phosphorus levels in soil and in runoff from corn production systems. J Environ Qual 32:310-316

Bray RH, Kurtz LT (1945) Determination of total, organic, and available form of phosphorus in soils. Soil Sci 59:39-46

Bremmer JM (1965) Inorganic forms of nitrogen. In: Black CA (ed) Methods of soil analysis. American Society of Agronomy. Madison, Wisconsin

Bueno JM, Sáez-Plaza P, Ramos-Escudero F, Jiménez AM, Fett R, Asuero AG (2012) Analysis and antioxidant capacity of anthocyanin pigments. Part II: Chemical structure, color, and intake of anthocyanins. Cr Rev Anal Chem 42:126-151

Caplan JS, Yeakley JA (2013) Functional morphology underlies performance differences among invasive and non-invasive ruderal Rubus species. Oecologia 173:363-374

Challenger A (1998) Utilización y Conservación de los Ecosistemas Terrestres de México. Pasado, Presente y Futuro. CONABIO, Mexico City

Conesa MA, Musi M, Roselló JA (2012) Leaf shape variation and taxonomic boundaries in two sympatric rupicolous species of Helichrysum (Asteraceae:
Gnaphalieae), assessed by linear measurements and geometric morphometry. Biol J Linn Soc 106:498-513

Dillion ME, Frazier MR, Dudley R (2006) Into thin air: Phisiology and evolution of alpine insects. Integr Comp Biol 46:49-51

Donahue RL, Miller RW, Shickluna JC (1997) Soils: An introduction to soils and plant growth. Prentice-Hall International, Englewood

Driessen P, Deckers J (eds) (2001) Lecture notes on the major soils of the world. Food and Agriculture Organization of The United Nations, Rome, 334 pp

Farooq M, Wahid A, Kobayashi N, Fujita D, Basra SMA (2009) Plant drought stress: effects, mechanisms and management. Agron Sustain Dev 29:185-212

Funk VA, Susanna A, Stuessy TF, Baller RJ (2009) Systematics, evolution and biogeography of Compositae. Internacional Association for Plant Taxonomy. University of Vienna, Vienna

Galicia L, García-Romero A (2007) Land use and land cover change in highland temperate forests in the Izta-Popo National Park, central Mexico. Mt Res Dev 27:48-57

Geng Y, Pan X, Xu C, Zhang W, Li B, Chan J (2006) Phenotypic plasticity of invasive Iternanthera philoxeroides in relation to different water availability compared to its native congener. Acta Oecol 30:380-385

Hobbs RJ, Huenneke LF (1992) Disturbance, diversity, and invasion: implications for conservation. Conserv Biol 6:324-337

Holmgren M, Gómez-Aparicio L, Quero JL, Valladares F (2011) Non-linear effects of drought under shade: reconciling physiological and ecological models in plant communities. Oecologia 169:293-305

Kieltyk P, Mirek Z (2014) Taxonomy of the Solidago virgaurea group (Asteraceae) in Poland, with special reference to variability along an altitudinal gradient. Folia Geobot 49:259-282

Kollmann J, Bañuelos JM (2004) Latitudinal trends in growth and phenology of the invasive alien plant Impatiens glandulifera (Balsaminaceae). Diversity Distrib 10:377-385

Kuta E, Jezdrzejczyk-Koryciska M, Cieslak E, Rostanski A, Szczepaniak M, Migdałek G, Wasowicz P, Suda J, Combik M, Słomka A (2013) Morphological versus genetic diversity of Viola reichenbachiana and V. riviniana (sect. Viola, Violaceae) from soils differing in heavy metal content. Plant Biol 16:924-934

Lavorel S, Grigulis K (2012) How fundamental plant functional trait relationships scale-up to trade-offs and synergies in ecosystem services. J Ecol 100:128-140

Leiss KA, Müller-Schärer H (2001) Adaptation of Senecio vulgaris (Asteraceae) to ruderal and agricultural habitats. Am J Bot 88:1593-1599

López-Bucio J, Cruz-Ramírez A, Herrera-Estrella L (2003) The role of nutrient availability in regulating root architecture. Curr Opin Plant Biol 6:280-287

Manivannan P, Jaleel CA, Somasundaram R, Panneerselvam R (2008) Osmoregulation and antioxidant metabolism in drought stressed Helianthus annuus under triadimefon drenching. Comp Rend Biol 331:418-425

Marschner H (2002) Mineral nutrition of higher plants. Academic Press, London

Medina Lemus JG, Tejero-Díez J (2006) Flora y vegetación del parque estatal Atizapán-Valle Escondico, Estado de México, México. Polibotánica 21:1-43

Moles AT, Warton DI, Warman L, Swenson NG, Laffan SW, Zanne AE, Pitman A Hemmings FA, Leishman MR (2009) Global patterns in plant height. J Ecol 97:923-932

Mozaffari K, Arshi Y, Zeinali-Khanghaa H (1996) Research on the effects of water stress on some morphophysiological traits and yield components of sunflower (Helianthus annuus L.). Seed Plant 12:24-33

Nicotra AE, Atkin OK, Bonser SP, Davidson AM, Finnegan EJ, Mathesius U, Poot P, Purugganan MD, Richards CL, Valladares F, van Kleunen M (2010) Plant phenotypic plasticity in a changing climate. Trends Plant Sci 15:684-692

Paniagua-Ibañez M, Zepeda-Rodríguez A, Mussali-Galante P, Ramírez-Rodríguez R, Tovar-Sánchez E (2014) Micro and macro- morphological variation of Cosmos bipinnatus and Cosmos bipinnatus var. albiflorus in symatric zones in central Mexico. In: Ignacio Ribas I (ed) Sunflowers. Growth and development, environmental influences and pests/diseases. Nova Publishers, New York

Ponsie ME, Johnson SD, Edwards TJ (2009) A morphometric analysis of the Bonatea speciosa complex (Orchidaceae) and its implications for species boundaries. Nord J Bot 27:166-177

Price CA, Weitz JS (2012) Allometric covariation: a hallmark behavior of plants and leaves. New Phytol 193:882-889

Ramamoorthy TP, Bye R, Lot A, Fa J (1993) Biological diversity of Mexico. Oxford University Press, New York, Origins and distribution

Ran F, Zhang X, Zhang Y, Korpelainen H, Li C (2013) Altitudinal variation in growth, photosynthetic capacity and water use efficiency of Abies faxoniana 
Rehd. et Wils. seedlings as revealed by reciprocal transplantations. Trees 27:1405-1416

Reed DH, Frankham R (2001) How closely correlated are molecular and quantitative measures of genetic variation? A meta-analysis. Evolution 55:1095-1103

Rzedowski J (1978) La vegetación de México. Limusa, Mexico City

Rzedowski GC, Rzedowski J (2001) Flora fanerogámica del valle de México. Instituto de Ecología and Comisión Nacional para el Conocimiento y Uso de la Biodiversidad, Michoacán

Salisbury FT (1968) Las plantas vasculares: Forma y función. Herrero Hermanos Sucesores, Mexico

Schlichting CD (1986) The evolution of phenotypic plasticity in plants. Ann Rev Ecol Syst 17:667-693

Semir J, Loeuille B, Monge M (2014) The Lychnophora granmogolensis (Asteraceae-Vernonieae) species complex: two new species and comments on the identity of Lychnophora granmogolensis. Syst Bot 39:988-996

Specht JE, Chase K, Macrander M, Graef GL, Chung J, Markwell JP, Germann M, Orf JH, Lark KG (2001) Soybean response to water. A QTL analysis of drought tolerance. Crop Sci 41:493-509

Stenøien HK, Hassel K, Segreto R, Gabriel R, Karlin EF, Shaw AJ, Flatberg KI (2014) High morphological diversity in remote island populations of the peat moss Sphagnum palustre: glacial refugium, adaptive radiation or just plasticity? Bryologist 117:95-109

Tetsana N, Pedersen ÆH, Sridith K (2014) Character intercorrelation and the potential role of phenotypic plasticity in orchids: a case study of the epiphyte Liparis resupinata. Plant Syst Evol 300:517-526

Trubat R, Cortina J, Vilagrosa A (2006) Plant morphology and root hydraulics are altered by nutrient deficiency in Pistacia lentiscus (L.). Trees 20:334-339

Turner BL, Nesom GL (1998) Biogeografía, diversidad y situación de peligro o amenaza de Asteraceae de México. In: Ramamoorthy TP, Bye R, Lot A, Fa J (eds) Biological diversity of Mexico. Origins and distriburion. Instituto de Biología, UNAM, Mexico

Valladares F, Sánchez-Gómez D, Zavala MA (2006) Quantitative estimation of phenotypic plasticity: Bridging the gap between the evolutionary concept and its ecological applications. J Ecol 94:1103-1116

Vargas-Amado G, Castro-Castro A, Harker M, Villaseñor JL, Ortiz E, Rodríguez A (2013) Geographic distribution and richness of the genus Cosmos (Asteraceae: Coreopsideae). Rev Mex Biodivers 84:536-555

Vitasse Y, Lenz A, Kollas C, Randin CF, Hoch G, Körner C (2013) Genetic vs. nongenetic responses of leaf morphology and growth to elevation in temperate tree species. Funct Ecol 28:243-252.

Wullschleger SD, Yin TM, DiFazio SP, Tschaplinski TP, Gunter LE, Davis MF, Tuskan GA (2005) Phenotypic variation in growth and biomass distribution for two advanced-generation pedigrees of hybrid poplar. Canadian J For Res 35:1779-1789

Zar JH (2010) Biostatistical analysis. Prentice Hall, New Jersey

Zhang M, Duan L, Zhai Z, Li J, Tian X, Wang B, He Z, Li Z (2004) Effects of plant growth regulators on water deficit-induced yield loss in soybean. Proceedings of the 4th International Crop Science Congress, Brisbane, Australia

\section{Submit your manuscript to a SpringerOpen ${ }^{\circ}$ journal and benefit from:}

- Convenient online submission

- Rigorous peer review

- Immediate publication on acceptance

- Open access: articles freely available online

- High visibility within the field

- Retaining the copyright to your article

Submit your next manuscript at $>$ springeropen.com 